\title{
Can movies and media offer an easily accessible, dynamic resource to enrich and expand our English language teaching?
}

\author{
Shadi Afzal \\ Department of English, Beyza Branch, Islamic Azad University, Beyza, Iran
}

\section{Email address:}

shadi.afzal@yahoo.com

\section{To cite this article:}

Shadi Afzal. Can Movies and Media Offer an Easily Accessible, Dynamic Resource to Enrich and Expand Our English Language Teaching? International Journal of Language and Linguistics. Vol. 1, No. 4, 2013, pp. 160-165. doi: 10.11648/j.ij11.20130104.20

\begin{abstract}
This study investigates 10 teachers' view and attitude toward using media, such as TV, movies and music as a tool in language learning, so the aim of this study is to look at how film and media can be seen as resources in teaching and also find out how teachers use and regard film and media in education. Ten upper-intermediate teachers of one of the English language institute of Shiraz were interviewed for this study. Teachers feel that one of the positive aspects of working with media is that there is an enormous amount of material to draw inspiration from and that it provides the students with an opportunity to get exposed to different accents of the English language, so the interviewed teachers expressed that films offers authentic target language input. According to the interviewed teachers a "film experience" is regarded as a powerful tool for starting a discussion or introducing a theme. The use of film can also benefit students with different learning styles. It is also likely that students' positive perception of film in teaching has effects on language learning since motivation and attitudes, according to research, affect language acquisition. The results suggest that teachers generally are positive to the use of film in education and believe that students can learn many things from audio-visual media.
\end{abstract}

Keywords: Language Acquisition, Multimedia in Education, Teaching English, Second Language Learners

\section{Introduction}

In today's society we have become accustomed to having radios, TVs, computers and mobile phones always within reach and nearby. In a blink of an eye we can call home or read a newspaper that has been published on the other side of the world. We live in an age of technology and fast communication, where almost everything seems possible.

$\mathrm{TV}$, computers and mobile phones were mere fictions 60 years ago. Today such technology can be found in most households. In my opinion, technology has increased our knowledge and understanding of the world in a number of ways. It has helped us become more time efficient, but one could also argue that it has to some extent taken over and consumed what was left of our spare time. Since most of us have these technologies with us and have grown to be more or less dependent upon them, our spare time has become a thing of the past. Outside of work we constantly answer the mobile work phone or check e-mails. Despite their drawbacks, most people would probably agree that they in spite of this have changed our lives for the better.

The invention of these types of technologies has changed so much, for instance how we view and define a text. The word "text" has many possible definitions; some consider text to be only written texts, while others view text as anything that has some sort of meaning, including signs and pictures.

When the new syllabus for English appeared in 1994, it stated that although text is predominantly seen as written text within the education system, the syllabi recognized the importance of using film as a tool in teaching (Skolverket, retrieved 2010-04-10). Since there are so many possible meanings of the word text it is necessary to establish a definition of how the word will be used in this particular degree project. The Longman Dictionary of Contemporary English defines text in the following way, "any written material". However, there are other possible definitions of the word. The syllabus for English mentions that "text can be seen as more than written text; text can also be pictures or moving images" (Skolverket, Retrieved2010-04-10). The definition used by the Longman Dictionary of 
Contemporary English is too narrow to suit the aims of this study so I would like to broaden the definition of the word "text". Christina Olin-Scheller has conducted research on the difference between how different generations define and view text, "since Lpo 94 text is now not only seen as books but also includes new media such as movies, TV and computer games. However, new media is not currently used as regularly as books in education" (Christina Olin-Scheller, retrieved from 2010-07-12, own translation). It is this broader use I will be referring to from here on when I mention text. It is our duty as teachers to make sure that our students realize and familiarize themselves with texts of all sorts.

By investigating how different English teachers use TV, movies and music to help their students expand their knowledge of the English language and culture, I hope to learn new ways of integrating different types of texts into my future classroom. One of the problems that we as teachers face is getting our students motivated and interested in learning. I am of the opinion that if the students are motivated and enjoying themselves, learning becomes easy and fun. Our students come in contact with these different types of media outside of school and therefore they are already familiar with them. Education is supposed to be individualized to suit every student's separate need and therefore it could be very valuable and stimulating to incorporate the students' interests and experiences into the English classroom.

Using various kinds of Media in the classroom has always been a challenge, and how to bring these Media in the classroom is more than a challenge. Students and teachers should be able to use in their classrooms different media through different technologies. Media provide teachers and students with creative and practical ideas. They enable teachers to meet various needs and interests of their students. They also provide students with a lot of language practice through activities using newspapers, magazines, radio, TV, movies, books, Internet, etc, and tasks which develop reading, writing, speaking and listening skills. They entertain students and encourage reading English in general, both inside and outside the classroom, promoting extensive reading by giving the students the confidence, the motivation and the ability to continue their reading outside the classroom.

Bearing in mind all these features and positive input of Media in Education I thought to undertake this study to give my modest contribution to the enhancement of teaching and learning English.

\subsection{Why are the Media Important}

Media are important because we get to know the world through using them; we understand the world and try to change it.

"We live in a world where media are omnipresent. An increasing number of people spend a great deal of time watching television, reading newspapers and magazines, playing records and listening to the radio... The school and the family share the responsibility of preparing the young person living in a world of powerful images, words and sounds" (UNESCO Declaration on Media, 1982)

Media Education is important because it develops students' creative powers for those images, words and sounds that come to the students from various Media. Thus, creating more active and critical media users, who will always be more demanding in the future.

Media Education has to do with film and television, press and radio, their impact on the students' progress. It has to do with what to teach through media, when and how. Its aim is to enable students to develop critical thinking, analyzing and reflecting on their experiences while using various means of Media.

\subsection{Teaching Film}

Movies produce an emotional response in audiences. We can be amused, frightened, excited; we can experience sorrow, pity, tension, patriotism, revulsion. In fact, any human emotion can be induced by a well-made film. Many movies are designed to pull the audience into the story- to identify strongly with, or at least to care about, the central character-to provide audiences with a vicarious experience in an "other world," and above all, to make audiences forget they are watching a movie. Audiences are influenced to react to situations and conditions; to believe in the veracity of events; to accept the ideas and ideals promoted in the film; and to adopt values, interpretations and perspectives. An audience can even be persuaded to buy products that are placed in scenes, especially when these products are seen as contributing to the enjoyment, relief and/or success of characters who use them. Cinema presents a powerful influence that contributes to cultural change, coaching us to accept or reject aspects of our society, inspiring the way we dress, popularizing our expressions, shaping language and meaning. In choosing films for classroom study, teachers, schools and/or school jurisdictions need to consider how well the film will help students meet the outcomes, but they must also consider the quality of the film, appeal and appropriateness for students, community standards, copyright concerns, cost and availability. Because students must become critical viewers of nonprint media, the films chosen for classroom study often deal with sensitive issues. Therefore, care must be taken both in the choice of films and in the kinds of learning activities that are planned around the films.

Today, film and streaming media are naturally part of young people's lives. According to statistics, young people between 15-24 are the most active media consumers. They spend on average about seven hours each day using the Internet, watching TV, watching film, reading newspapers and listening to the radio.More than $50 \%$ of young people aged 9-24 state that they watch video clips on the Internet, for example, on you tube every day (Nordicom-Sweden, 2009). 
It is important for teachers and people who work with children to be aware of the role of media and popular culture in young people's lives. It is a challenge to have an open and flexible approach to film, TV. And other media products.

Professor Larry M. Lynch thinks that movies can be a valuable language teaching tool.He has listed five good reasons why teachers should use popular movies with their students for English language practice and acquisition.

1. Movies in English are widely enjoyed; a wide variety of learner types enjoy watching movies. It is a resource that you can extract considerable mileage on a wide range of themes and topics.

2. Movies in English are easily available; English movies are extremely easy to find. Rental shops, book stores, theaters, media outlets, record shops and music stores all have numerous titles available at any given time.

3. Different movie formats; you have the option of using whatever format you like best, VHS, DVD or BETA.

4. The length of viewing is controllable; no matter what length classes you have, movies can be adapted to suit the timeframe you have available. Simply use clips from movies or installments instead of the whole movie.

5. Use of sub-titles is controllable; using sub-titles in English not only provides listening comprehension support, but aids in vocabulary development and reading comprehension as well (Lynch, retrieved 2010-04-21). This shows that movies can offer us an easily accessible, dynamic resource to enrich and expand our English language teaching.

Apart from TV and movies there is also research that claims that music is beneficial for second language learners. Professor Suzanne L. Medina expresses the benefits that working with music can bring to language learners in the following way:

Singing songs and listening to music are enjoyable experiences and as students repeatedly work with music, their confidence level rises. By engaging in a pleasurable experience, learners are relaxed and their inhibitions about acquiring a second language are lessened (Medina, retrieved 2010-04-23).

Medina emphasizes that music in the second language classroom is beneficial on many levels.

When second language learners hear songs, which are stories that have been set to music, it is possible to acquire vocabulary. It is therefore, in the interest of the second language teacher to provide an environment which evokes positive emotions. Music does precisely that (Medina, retrieved 2010-04-23).

In this study, the didactic potentials and the use of film and streaming media are studied in relation to the learning and teaching of English as a second language. My personal experience shows that film is sometimes regarded as valuable teaching material and other times only used for amusement or as a time-filler.

\section{Research Design}

\subsection{Questions}

The main questions at issue for this study are:

(1)What didactic potentials are there film and streaming media in English teaching?

(2)How do teachers use film and streaming media in the classroom?

(3)How do teachers regard film and streaming media as teaching resources?

\subsection{Material}

The material used for this study is based on interviews with ten teachers of the institutes of Shiraz. The main focus is on teachers' experiences and thoughts about film and streaming media in the teaching and learning of English.

The study is limited to film and streaming media but TVwatching is also discussed to some extent. The interactive use of the Internet in social networks and blogs are not part of this study.

\section{Methods and Procedures}

I have always enjoyed watching movies and I have come to realize that it is possible to learn a lot of English from watching and following along with a movie. By observing what is happening, listening to the language and reading the subtitles, one could acquire vocabulary and pronunciation, and one's ability to read could possibly be developed.

In this study, the respondents are ten upper-intermediate English teachers who teach in one of the institute of Shiraz. They were contacted and asked if they would like to be interviewed and all of them consented. According to Trost (2005), it is not necessary to have a completely representative sample from the population in a qualitative study. It is more important that the respondents are as different as possible from each other so that the answers that are obtained reflect many different ideas and opinions. The teachers that participated in this study have different experiences in teaching because they have taught at least for 6 years and also work in different institutes now. All of the ten teachers are women.

The respondents are called Teacher 1,2,3,4,5,6,7,8,9,10 in the results discussion. The interviews are confidential and when the respondents are described as a above, it is important not to make the information about the person so detailed that she can be recognized (Patel \& Davidson, 2003). In this case, the names of the institutes have not been inserted since it might identify the teachers.

The method used for this study is the interview method, which is used to collect data that is difficult to access by observations and questionnaires. There are many different types of interviews but there are essentially two kinds used for the purpose of research. They are: 
1. Exploratory interviews, depth interviews or free-style interviews.

2. Standardized interviews such as, for example, in public opinion polls, market research and government survey (Oppenheim, 1992).

A semi-structured exploratory interview method was used for this study. The interview mostly took the form of a discussion but some specific questions were also asked. Find the interview questions attached (Appendix 1).

The purpose of an exploratory interview is to try to understand how the respondents think and feel about the topic and not primarily to gather facts. Oppenheim (1992), explains the task of the depth interviewer in this way "The job of the depth interviewer is thus not that of data collection but ideas collection" nevertheless some factual questions were also asked.

When it comes to interviews there are two main ways of collecting data or ideas. These are either by taking notes or by recording the interviews. There are advantages and disadvantages associated with both of these strategies. Because recording can make respondents uneasy or unwilling to reveal sensitive information and also take a long time to transcribe, the researcher chose note taking approach.

Note-taking gives the interviewers an instant record of what has been said. All the interviews that were conducted for this study were held at the respondents' working-places. The interviews took about 25 minutes. The data obtained from interviews can be analyzed in many different ways, since the data is not countable, the analysis is qualitative. The main approaches to qualitative analysis are: case studies, content analysis, discourse analysis and multi method approaches (kaets, 2000). In this study, the content analysis approach was used. The answers are presented under different headings in the results section and commented.

\section{Results}

In this section the results from the teacher interviews are presented. The teachers' answer and comments are listed under the topics: thoughts about film in English teaching, description of how film is used in teaching, ideas about what students can learn from watching film, identified difficulties and negative aspects.

\subsection{Thoughts about Film in English Teaching}

All teachers who participated in this study stated that they use films in their teaching to some extent. Some teachers were very positive to film and those teachers didn't find that there are many difficulties connected with the use of film.

The teachers generally thought that it is good to use film in teaching as long as it is done in a professional way and with a well defined aim. The more experienced teachers generally had more well thought-out ideas about film in teaching. These are some of their comments:

Film is more dynamic than the textbooks. Using film in teaching English is a kind of entertainment so it is motivating, meaningful and also authentic. It's an interactive way of getting students' attention and interest. (Teacher 8)

Film can be good but also difficult to use. I teach many students who are very shy or not motivated, so it is difficult to get them to participate in a film discussion. (Teacher 3)

Using different kinds of film in teaching English definitely improve language skills such as Listening and speaking, but we shouldn't consider the film as a magicstick and only because it is new, something new does not necessary mean that it is good. Sometimes it is not useful or valuable in the classroom. (Teacher 6)

Sometimes film is an easy solution if I have to go to a meeting or something. I give the students a film to watch and then asked them to write about it, so sometimes I used it in emergencies as a time-filler. (Teacher 10)

\subsection{Description of How Film is Used in Teaching}

All teachers described how they analyze films in different ways together with the students. Discussions were mentioned as very common and according to the teachers, discussions or written assignments are most often based on a number of different questions that regard, for example, the plot, the message, the characters.

I let the students watch the film and then I ask a large number of questions. The questions might be rather simple but they can also be more analytical, it depends on the level of the students. (Teacher 9)

Before showing the film, I introduce new vocabularies used in the film and after watching, the students are given some assignments to do. The assignments that we do in connection to films varies very much. It depends on what type of film it is. Sometimes we have a classroom discussion, sometimes they do written assignments, sometimes I ask them to describe the characters of the film. (Teacher 5)

I use film to practice pronunciation and sometimes I look at film technicalities or work with different film genres. I often show films in class in English and with subtitles, the use of English subtitles makes it possible to watch rather difficult films. (Teacher 1)

\subsection{Ideas about What Students Can Learn from Watching Film}

All the teachers believed that students can learn very much from watching film. According to the teachers, students can improve their receptive skills by listening and by reading English subtitles. If there is a discussion after the film, they also improve their communicative skills as they talk about a common experience with their classmates. Students also learn about cultural differences and get different perspectives of their experiences. 
Students first improve their Listening skill but they can also look at the body-language to try to understand what the characters are saying. (Teacher 4 )

They use different types of expressions and speech in different situations and to different people .They understand if some expressions are rude or if they are informal or formal, and it is very useful to discuss different issues with them after the film. (Teacher 7)

They try to understand vocabularies to communicate with the concepts of the film and also the students became familiar with different cultures and also it is useful for students who have difficulties in concentrating and sitting down (Teacher 1)

\subsection{Identified Difficulties and Negative Aspects}

In today's classroom, teachers are pressed to make every minute count. If the teacher and students are not experienced with technology in the classroom, valuable time is often wasted on technical troubles. In addition, the teacher faces the difficulty of having a class full of students who are all at different skill levels. In many institutes, most students will have a computer and Internet access, but institutes that are located in impoverished areas may have a large portion of their student body with little to no computer experience. While it is important to educate these children in technology, it must be done at a pace that meets every individual's needs or more learning time will be wasted.

Another difficulty and negative aspect of the films in teaching are linked to the students' behavior or habit. Since most students are used to watching film in their spare time, they adapt the same habit while watching film in the classroom environment.

A problem is that when a film is presented they expect to watch it in the same lazy way as they do at home. They are used to watching film without thinking and without analyzing what they see. (Teacher 2)

There are some difficulties connected with the technical equipment that is necessary to show films or streaming media. Sometimes the equipment was difficult to get hold of and manage and they are so time-consuming. (Teacher 10)

\section{Discussion}

As mentioned, the aim of this study is to look at the didactic potentials of film and streaming media in English teaching and also give a picture of how teachers use film in the classroom and how they regard film in teaching. Several didactic potentials of film in English teaching are, hence, suggested by this study.

It is possible to say that a "film experience" is a part of a social context and can be a starting point for discussion. It can also trigger reflective thinking. Film is also good tool for students who have different learning styles, since the image and sound offer something different than a written text. According to research, second language acquisition is affected by personal characteristics such as attitude and motivation. It is therefore, likely that students' positive perception of film in teaching benefits language learning.

The second and third questions at issue for this study were aimed at exploring how teachers use film and streaming media in the classroom and how they regard film and streaming media as teaching resources. Earlier research shows that teachers often focus on written texts as teaching material and that film is used occasionally as an alternative (NAE, 2006).

The teachers generally have great belief in what students can learn from watching film and they are positive about the use of film in teaching if it is used in a good way. They all underline that it is necessary to make something more out of the watching of the film and that is the responsibility of the teacher to take the students' experience one step further.

Ohlin-sheller (2006) found in her study that film is often used as a time-filler or for amusement on a Friday afternoon. Some of the teachers who were interviewed for this study confess that they occasionally use film as a time filler or when they have to go somewhere.

The results of this study, hence, show that teachers generally regard film as a resource in English teaching. The possibility to watch, listen and read is perceived as positive for language learning. Most of the teachers also find that it is good to use film as the base for discussion. The passivity that is connected to film-watching and time-consuming use of the equipment, are regarded as the most negative aspects of the use of film in education.

\section{Conclusion}

The results of this study suggest that film can be regarded as a resource in teaching for several reasons. According to the interviewed teachers, a "film experience" is regarded as a powerful tool for starting a discussion or introducing a theme. The use of film can also be good for students with different learning style.

The teachers also expressed that film offers authentic target language input. The results also suggested that teachers generally are positive to the use of film in education and believe that students can learn many things from audio-visual media.

The interviewed teachers use film in their teaching in several ways and point out that, in this context. The role of the teacher is very important.

We are becoming more and more dependent on technology even in the field of education. Media can be a fantastic tool that is very versatile and useful in order to promote language learning. We as teachers can use media as a way of incorporating our students' experiences and everyday lives into the field of education. Media is a tool that can be molded to suit different needs and resources. The only limits are our own creativity and our willingness to try new things with our students. 


\section{Appendix A}

\section{Interview Questions}

1. What is your idea about the use of film in English teaching?

2. Can you describe how you have used film in teaching?

3. What do you think students can learn from watching film?

4. Do you use streaming media in your teaching?

5. What approach do students generally have to the use of film in teaching?

6. What are the negative aspects of using film? Are there any difficulties?

\section{References}

[1] Keats,D.(2000) Interviewing - a practical guide for students and professionals. Adelaide, Australia: Griffin press

[2] Lynch, Larry, 5 Reasons to use Popular Movies for English language Teaching, retrieved from http://ezinearticles.com/?5-Reasons-to-Use-PopularMovies-for-English-Language-Teaching\&id=287405, 2010$04-21$.
[3] Medina, Suzanne, Using music to Enhance Second Languag Acqusition: From Theoryto Practice, retrieved from http://www.forefrontpublishers.com/eslmusic/articles/06.ht $\mathrm{m}, 2010-04-23$

[4] National Agency for Education.(2006) Curriculum for noncompulsory school system (Lpf 94). Stockholm: Skolverket

[5] Nordicom-Sweden.(2009) Mediebarometern 2009. www.nordicom.gu.se read 11/5/2010

[6] Olin-Scheller, Christina, Kollision när elevens textvärld möter skolans, retrieved from http://www.skolporten.com/art.aspx?id=a0A200000001BW Q\&typ=art, 2010-07-12.

[7] Ohlin-sheller, C.(2006) Between Dante and big brother: textual worlds of Swedish upper secondary school studies. Dissertation. Karlstad University Studies.2006:67

[8] Patel, R \& Davidson, B.(2003) Forskningsmetodikens grunder: att planera, genomföra och rapporter en undersökning. Lund: Studentlitteratur Skolverket, retrieved from http://www.skolverket.se/ki03/front.aspx?sprak=EN\&ar=09 10\&infotyp=23\&skolform=11\&id=3870\&extraId=2087. 2010-04-10.

[9] Trost, J. (2005) Kvalitativa intervjuer. Lund: Studentlitteratur 